\title{
REMARKS ON EMBEDDING RESULTS OF SINE SERIES
}

\author{
D. S. YU AND S. P. ZHOU
}

Abstract. We consider some embedding relations among many important functional classes, such as $S_{p}(\lambda), H_{S, \beta}^{\omega}, H_{\beta}^{\omega}$ etc..

Mathematics subject classification (2000): 26A15, 42A10.

\section{REFERENCES}

[1] R. J. LE AND S. P. ZHOU, A new condition for the uniform convergence of certain trigonometric series, Acta Math. Hungar., 108 (2005), 161-169.

[2] L. LEINDLER, On the uniform convergence and boundedness of a certain class of sine series, Anal. Math., 27 (2001), 279-285.

[3] L. LEINDLER, Embedding results pertaining to strong approximation of Fourier series II, Anal. Math., 23 (1997), 223-240.

[4] L. LEINDLER, Embedding results regarding strong approximation of sine series, Acta Sci. Math. (Szeged), 71 (2005), 91-103.

[5] R. TABERSKI, Differences, Moduli and derivatives of fractional orders, Commentat. Math., 19 (1976-1977), 389-400.

[6] S. Yu. TikHonov, Generalized Lipschitz classes and Fourier series, Math. Zametki, 75(2004), 947-951; translation in Math. Notes, 75 (2004), 885-889.

[7] D. S. YU AND S. P. ZHOU, A new generalization of monotonicity and applications, Acta Math. Hungar., 115 (2007), 247-267. 